\title{
(Re)pensando paradigmas: a História Cultural do Político e a construção do Estado Nacional na Espanha - comentário ao texto de Juan Pro Ruiz.
}

Rethinking paradigms: the Political-Cultural History and the National State building

DOI in Spain - comments on the Juan pro Ruiz's text.

http://dx.doi.org/10.1590/2236-463320161302

Izabel Andrade Marson

Universidade Estadual de Campinas, São Paulo - SP, Brasil

iamarson@gmail.com

\section{Resumo}

Este comentário está organizado em duas partes: a primeira resume proposições de Juan Pro Ruiz e sua contribuição para os estudos da história político-cultural do liberalismo na Espanha do século XIX. Destaca especialmente a crítica às concepções que restringem a figura do Estado a seu aparato fiscal e militar ignorando dispositivos político-culturais que moldaram a "mentalidade nacional". A segunda parte focaliza conceitos importantes do texto -- revolução/ ruptura/Antigo Regime - - e as relações entre Estado, Nação e Cultura Política.

\section{Abstract}

This comment is organized in two parts: the first one summarizes Juan Pro Ruiz's propositions and his contributions to the studies on the politicalcultural history of Spanish liberalism in the XIX century. Especially, it emphasizes the criticism to the conceptions that limit the image of the State to its fiscal and military institutions, by ignoring the State's political and cultural instruments that shaped the "national mentality". The second part focuses on the analysis of important concepts of the text -- revolution/ rupture/ Ancient Regime - and on the relationships between State, Nation and Political-Culture.

Palavras-chave

Estado, Cultura Política; Liberalismo; Mentalidade Nacional.

Keywords

State; Political-Culture; Liberalism; National Mentality. 
LEFORT, Claude. Pensando o político. Ensaios sobre democracia, revolução e liberdade. Trad. Eliana M. de Souza. Rio de Janeiro:Paz e Terra, 1991. p.13.

Sobre a história deste tema lembro:BALAKRISHNAN, Gopal; ANDERSON, Benedict. (orgs.). Um mapa da questão nacional. Trad. Vera Ribeiro. Rio de Janeiro: Contraponto, 2000; PALTI, Elias José. La nación como problema. Los historiadores y la "cuestión nacional." México: Fondo de Cultura Económica, 2003; XAVIER-GUERRA, François; ANNINO, Antonio. (orgs.). Inventando la nación: Iberoamérica. Siglo XIX. México: Fondo de Cultura Económica, 2003. No que diz respeito ao Brasil, cf. JANCSÓ, István. (org.). Independência: história e historiografia. São Paulo: Hucitec: Fapesp, 2005

Ver PRO RUIZ, Juan. La construcción del Estado en España: haciendo historia cultural de lo politico, publicado neste número da Revista Almanack.

DÉLOYE, Yves. A cidadania europeia sob o prisma de suas fronteiras [ou] como pensar o pertencimento político em um mundo pós-westfaliano. In: NAXARA, Marcia; MARSON, Izabel; BREPOHL, Marion. (orgs.). Indiferenças. Percepções políticas de um sentimento. São Paulo:Intermeios, 2015. p. 39-56.
Pensar o politico, em nosso tempo, requer uma sensibilidade ao histórico que não anula mas, ao contrário, torna mais necessário o abandono da ficção hegeliana ou marxista da história. Apenas perscrutando os sinais do novo, perguntando o que advém com a formação e o desenvolvimento da democracia moderna [...] é que temos alguma oportunidade de avaliar o político, como outros souberam faze-lo no passado, a partir de uma experiência distinta, e, alguns, com uma acuidade e uma audácia incomparáveis. ${ }^{1}$

Inicialmente quero agradecer o amável convite dos colegas da Almanack para integrar este Fórum, espaço de instigantes discussões teóricas e interpretativas de temas seminais da História Moderna da Europa e da América, em destaque a formação do Estado-nação durante o século XIX. Agradeço, em especial, a oportunidade de conversar com o prof. Juan Pro Ruiz (da Universidad Autónoma de Madrid), pesquisador dedicado a este assunto quando referido não apenas à situação espanhola mas, também, à análise comparada daquela experiência com a da América Hispânica, notadamente México e Argentina. Ao menos é o que demonstra sua atuação no projeto Imaginarios de Estado. Modelos, utopías y distopias en la construcción del Estado-nación español en perspectiva comparada (siglos XVII-XX), do qual o texto aquí abordado divulga resultados. Como veremos, Juan Pro Ruiz dedicou boa parte, senão toda sua carreira, à investigação de eventos e personagens partícipes da cultura política comprometida com a construção do Estado Nacional espanhol durante o século XIX, referência registrada em seu currículo e na argumentação do trabalho que vamos debater.

Entre o século XIX e o início deste século XXI o problema da formação das nações contemporâneas tem continuadamente interessado políticos e intelectuais de variada especialidade nos dois lados do Atlântico, de tal forma que, desde algumas décadas, já se constata uma história para o tema². Conforme bem registra Juan Pro Ruiz, neste percurso ressaltam-se os anos 1980-1990, momento em que o assunto ganhou renovado vigor nos meios políticos e acadêmicos do Ocidente - particularmente no campo da sociologia histórica realizada nos Estados Unidos, os State-building studies -, estimulados por acontecimentos de grande impacto internacional a exemplo do esfacelamento da União Soviética, da intervenção americana e europeia nos conflitos ocorridos nos Balcãs, e da (re)composição dos estados que integravam a antiga lugoslávia. Também, mais recentemente, nas tentativas de reconstrução do Afeganistão e do Iraque ${ }^{3}$, situações às quais eu ousaria acrescentar a criação da União Europeia, iniciativa que interferiu nos arranjos institucionais dos paises membros, incentivou sensivel polêmica sobre o tema da cidadania e (re)acendeu recorrentes desejos de independência em muitos estados, a exemplo, dentre outros, do País Basco e da Catalunha. ${ }^{4}$

Portanto, ao privilegiar a Espanha do século XIX, o texto retoma questões políticas e teóricas muito atuais inspiradas no "giro teórico culturalista" que, desde os anos 1980, mobiliza intelectuais de vários países e campos das ciências humanas alinhados, grosso modo, em duas tendências: de um lado, os defensores de tese mais antiga - from State to nation - que concebem o fenômeno nacional e o nacionalismo como "criação do Estado"; de outro, pesquisadores afinados com a tese from Nation to State, simpatizantes dos estudos político-culturais desenvolvidos no campo da antropologia e defen- 
Representam a tese from State to nation: Elie Kedourie, Ernest Gellner, Eric Hobsbawm, Benedict Anderson. Alinham-se com a interpretação from Nation to State: Pierre van der Berghe, Clifford Geertz, Susannah Fishman, dentre outros. Cf. SMITH, Anthony. 0 nacionalismo e os historiadores. In: BALAKRISHNAN, Gopal; ANDERSON, Benedict. (Orgs.). Op. Cit. p.185-208; CATROGA, Fernando. Pátria, Nação, Nacionalismo. In: TORGAL, Luís; PIMENTA, Fernando; SOUSA, Julião S. (coord.). Comunidades Imaginadas. Nação e nacionalismo em África. Coimbra: Imprensa da Universidade, 2008. p.9-40.

6

STEINMETZ, George. (ed.). State/Culture. State formation after Cultural Turn. Ithaca/ London:Cornell University Press, 1999; CORRIGAN, Philip; SAYER, Derek. The Great Arch: English state formation as cultural revolution. Oxford:Blackwell, 1985.

PRO RUIZ, Juan. La construcción del Estado em España... Op.cit

FEBVRE, Lucien. Combats pour I'Histoire. Paris: Armand Collin, 1953.

Veja-se especialmente o item "Los modelos em competência: imaginários de Estado", p. 27.

\section{0}

"The cultural turn encompasses a wide array of new theoretical impulses from fields formerly peripheral to the social sciences, as will as submerged within the social sciences themselves". STEINMETZ, George. (ed.). Op. Cit., p. 1.

11

Em várias circunstâncias, o texto retoma temas e referências do importante trabalho historiográfico de Miguel Artola sobre a história econômica e política contemporânea da Espanha. Juan Pro Ruiz participou da elaboração de verbetes [Gobierno, Cortes, Monedas, Pesos e Medidas] da Enciclopédia da Historia da Espanha, dirigida por Artola. ARTOLA GALLEGO, Miguel (dir.); PÉREZ LEDESMA, Manuel. (col.); PRO RUIZ, Juan (col.). Enciclopedia de historia de España. Madrid:Alianza Editorial, 1988. vol. 6. p. 1095-1176; 1209-1237. sores da primazia da cultura latu sensu pré-existente na configuração dos estados nacionais do XIX, sobretudo os europeus ocidentais onde se reconhece intensa tradição de mobilização social. ${ }^{5}$

Recorrendo a eclético e criativo apoio teórico dos State-building studies representados primordialmente por trabalhos de George Steinmetz, Philip Corrigan e Derek Sayer ${ }^{6}$, a reflexão de Pro Ruiz retoma este debate sobre a montagem do Estado-Nação por ângulo inovador: preocupa-se em compreender a categoria Estado também de uma perspectiva "político-cultural". Em outros termos, amplia o seu perfil incorporando aos traços já clássicos (o sistema político-jurídico-fiscal-militar e o território), dispositivos culturais e imaginários políticos a ele atinentes decisivos na conformação das chamadas "mentalidades nacionais". Para tanto, valoriza procedimentos próprios do Estado na sua forma liberal -- práticas educativas, imaginários político-partidários, símbolos nacionais - que no geral escapam aos clichês institucionais e burocráticos. Entende este Estado como constructo histórico-social de amplo significado, discordando assim dos estudos que se concentraram primordialmente:

\begin{abstract}
"al redor del concepto de nación como si todo lo que esta palabra encierra pudiera funcionar como dimensión cultural del fenómeno, reservado el término estado para las dimensiones de carácter institucional, burocrático o material. Particularmente en paises en los que la identidad nacional sigue siendo hoy en día una cuestión política palpitante y conflictiva, como ocurre en el caso de España, la consideración de la construcción del Estado como proceso cultural (y no sólo político, jurídico, económico y social) ha derivado inevitablemente hacia la historia de la construcción de la nación, objeto esencialmente mental, lingüistico y cultural. Como en tantos otros aspectos, la nación oscurece más de lo que aclara, e impide ver otras dimensiones de un proceso histórico tan fuertemente cultural como fue - en España y en todas partes - la construcción del Estado".7
\end{abstract}

Também enriquece o tema ao analisá-lo historicamente em um estudo de caso - o espanhol - experiência desafiadora de modelos clássicos de estados-nação europeus, no geral reconhecidos nos exemplos da Inglaterra e da França. Eu creio que, assim como na história das nações hispano-americanas e do Brasil, a situação espanhola interroga esquemas interpretativos, ou "esquemas desencarnados" como diria Lucien Febvre ${ }^{8}$, delineados por imaginários e teorias "mecanicistas" aqui problematizadas. Preceitos destas teorias - em especial a concepção de progresso - fundamentaram tanto projetos emergentes no cenário da disputa política espanhola ao longo do século XIX, tão bem descritos na análise apresentada por Pro Ruiz, ${ }^{9}$, quanto interpretações de experiências europeias e americanas, não exemplares, divulgadas no século XX por leituras comprometidas com o liberalismo ou com a ortodoxia marxista.

Minha intervenção se organiza em duas partes. Na primeira apresento um dos possiveis entendimentos do texto que, à luz das discussões instigadas pelo "cultural turn" no campo da sociologia histórica, da antropologia, da historiografia thompsoniana ${ }^{10}$, sistematiza resultados de pesquisas precedentes do autor sobre vários assuntos, no seu conjunto, parecem-me, próximas de estudos consagrados de Miguel Artola sobre a história social da Espanha contemporânea"1. Lembro que Pro Ruiz já investigou exaustivamente questões econômicas (relativas à "Hacienda"), políticas ( elites, partidos, ministérios, programas ) e personagens de destaque na construção do 
A relação de publicações de Juan Pro Ruiz está disponivel em: http:dialnet.unirioja.es/servlet/ autor?codigo $=118342$.

13

Conferir a discussão sobre estes campos na Espanha em PÉREZ LEDESMA, Manuel; SIERRA, Maria.(eds.). Culturas politicas: teoria e historia. Zaragoza:Institución Fernando el Católico, 2010, coletânea na qual Juan Pro Ruiz publicou 0 capítulo "Estado y modernidade en el lenguage de los afrancesados".

14

Temas tangenciados em várias passagens, por exemplo, nas p. 20, 26, 30, 33.

15

PRO RUIZ, Juan. La construcción del Estado em España... Op.cit.

16

STEINMETZ, George. (ed.). Op.Cit. p. 1-2.

17

CORRIGAN, Philip; SAYER, Derek. Op.Cit.p. 1-11.

18

Na linha de estudos de Miguel Artola realizados nos anos 1990, a exemplo de: ARTOLA GALLEG0, Miguel. Antíguo Régimen y revolución liberal. Barcelona: Editorial Ariel, 1991.

19

PRO RUIZ, Juan. La construcción del Estado em España... Op.cit. estado espanhol do XIX -- Mendizábal, Narváez, Espartero, Javier Burgos, Bravo Murillo, os "afrancesados"12. Pode-se considerar que seus trabalhos anteriores (do final da década de 1980 e início da década de 1990), cujos resultados são fundamentais na argumentação do texto agora abordado, denotam referências amplamente praticadas naquele momento pela história social, posteriormente enriquecidas com conceitos e temas provindos das culturas políticas e da história cultural, em destaque, problemáticas das mentalidades, imaginários sociais e linguagens políticas. ${ }^{13}$

$\mathrm{Na}$ segunda parte anoto algumas questões que o texto, muito instigante, suscitou. Meu intuito, senão curiosidade é estabelecer uma conversa sobre os conteúdos de algumas categorias importantes na análise - Antigo Regime, revolução, ruptura, nação. Também sobre o percurso e opções do autor no estudo da formação/construção dos Estados-nação no Ocidente. Neles, percurso e opções, é possivel reconhecer preocupações de cientistas sociais sensiveis às indagações políticas do presente - no caso, sobre origens e permanências do "autoritarismo" e do "localismo" na política espanhola contemporânea, tanto em reverberações destes princípios nos regimes comandados por Primo de Rivera e pelo general Francisco Franco ${ }^{14}$ quanto na questão da "identidade nacional" que, em suas palavras, "sigue siendo hoy en dia una cuestión política palpitante y conflictiva".15 0 texto ainda denota sensibilidade atualizada para com o paradigma transdisciplinar originalmente proposto pelos fundadores e continuadores dos Annales. Embora atento às contribuições das ciências sociais clássicas - a sociologia, a antropologia e a economia - incorpora-as pelo viés sugerido por George Steinmetz, ${ }_{1}^{16} \mathrm{e}$ Corrigan e Sayer ${ }^{17}$, ou seja, valorizando as subjetividades, a cultura política, a história e seus personagens. Além desta proximidade com a história social a reflexão também sinaliza afinidades com orientações críticas das ortodoxias marxistas ${ }^{18}$.

Entendo que a reflexão de Juan Pro Ruiz se organiza em 3 movimentos: o primeiro problematiza paradigmas "mecanicistas" e restritivos, de diverso teor, que têm dominado os estudos antigos e recentes sobre o Estado na Espanha e fora dela; o segundo sugere outros fundamentos propostos pela história cultural do político para delinear aquele objeto; o terceiro faz uma demonstração histórica destas outras referências aplicando-as ao caso espanhol.

\section{Interrogando paradigmas da construção do Estado Nacional}

0 texto principia expondo discordâncias do autor em relação a dois "paradigmas" constitutivos "de las visiones clásicas de la construcción estatal" que dominaram e em grande medida continuam a dominar interpretações realizadas na Europa e nos Estados Unidos sobre a constituição dos Estados Nacionais. 0 primeiro deles diz respeito ao paradigma da continuidade como movimento progressivo, "en virtud del cual el Estado nacional contemporáneo se presenta como la culminación de un proceso iniciado con las monarquias en los siglos XV al XVII, de manera que el Estado de la Edad Contemporánea sería un perfeccionamiento del Estado embrionario conocido ya en la Edad Moderna". Tal compreensão admite também o "progreso continuo del que los ciudadanos de nuestro tiempo seriamos los felices beneficiarios"19.

0 segundo paradigma concebe o Estado moderno e contemporâneo como Estado-fiscal e militar (Fiscal-state), teoria veiculada em análises "objetivistas da sociologia histórica" anteriores ao cultural turn -- a de Charles 
Empresto a expressão do título da já mencionada obra "The Great Arch" de Philip Corrigan e Derek Sayer.

Mencionados no texto original disponibilizado para o debate.
Tilly, especialmente -- que enfatiza um dado perfil da construção do Estado - o processo material de acumulação de recursos em um Estado centralizado. 0 texto problematiza ambos os paradigmas apontando suas limitações teóricas: a concepção formal de Estado e a percepção "mecanicista" e progressista da História que os fundamenta "ignoram" os desempenhos dos atores históricos substituindo-os por:

"un mecanismo semiautomático de causas materiales en el cual se encadenan la acumulación de capital, la estructura de clases, la guerra, la fiscalidad y la burocracia, equiparando los procesos desarrollados en contextos culturales muy dispares. Pero de esta manera se ignora el sentido que los actores dieron al concepto de Estado y a su propia participación en la construcción del mismo".20

Por ignorar a participação daqueles atores, tais paradigmas tornam a História uma evolução naturalizada, constrangedora das sociedades e de seus integrantes, com percurso e ponto de chegada previamente definidos. Também pressupõem conceito restritivo do "fenômeno Estatal", materializado como Estado-fiscal militar circunscrito a uma estrutura burocrática de instituições formalizadas, sobretudo financeiras e político-jurídicas. Tal percepção omitiria dispositivos de teor cultural e subjetivo, também eles integrados ao conjunto das ações do Estado e com o importante papel político de formarem comportamentos significativos de uma "mentalidade nacional".

0 texto faz então um diagnóstico dos problemas metodológicos daquelas interpretações. Nelas se constataria "el divorcio inconcebible entre la tradición investigadora del Estado-fiscal militar y otras tradiciones igualmente ricas, pero desconectadas de aquella"22, estas últimas remetidas à história do pensamento político (história dos conceitos e das culturas políticas) e à história do direito, em especial os estudos das doutrinas jurídicas. É justamente uma "ponte" entre diversas tradições de estudo do Estado Nacional, dentre elas, inclusive, a história social das práticas econômicas, políticas e das mentalidades - - locus de origem dos estudos do autor -- que ele, parece-me, propõe estabelecer.

Acompanhando procedimentos e pressupostos de fundadores e divulgadores do "giro culturalista" que sinalizaram percepções mais complexas do fenômeno estatal, a reflexão de Juan Pro Ruiz estabelece amplo e criativo "Arco Teórico"23 visando superar o apontado "divórcio inconcebível". Esse "Arco" retoma argumentos da sociologia clássica (Max Weber), da antropologia política (Pierre Bourdieu), da história do pensamento político (Pierre Rosanvalon), da história do Direito (Manuel Hespanha) e da história dos conceitos de Reinhart Koselleck e Javier Sebástian ${ }^{24}$ - sobretudo destes últimos teóricos - para questionar as premissas de continuidade e evolução como fundamentos do movimento histórico, contrapondo a elas o pressuposto da "revolução como ruptura", em sentido amplo, ou seja, não restrito ao rompimento institucional ou à substituição de grupos no exercício do poder político, mas também em sua dimensão "cultural" - subjetiva, comportamental, intelectual.

Também se vale deste "Arco" teórico para ampliar o conceito de Estado, demonstrando-o enquanto vínculo, a um só tempo, material e sensivel, lugar de embates revolucionários na longa duração e de rompimentos de variado gênero - entre partidos, classes, projetos políticos e, especialmente, comportamentos, mentalidades e imaginários ${ }^{25}$. No caso espanhol, a cons- 
PRO RUIZ, Juan. La construcción del Estado em España... Op.cit.

26

Ibidem. trução do Estado teria ocorrido ao longo de um século e meio, conduzida por lideranças que, gradativamente implementaram alterações significativas, tanto materiais quanto nas sensibilidades políticas. Associadas, elas configuraram um complexo fenômeno coletivo: o Estado nacional:

"Al término de este proceso de conformación estatal de las mentalidades colectivas, el Estado es ya una realidad mental tanto más que una realidad institucional; es tanto interior o subjetivo como exterior u objetivo. Pero para llegar a ese resultad, ha sido necesario un proceso de cambio cultural, desde las formas no-estatales de convivencia y de institucionalización del poder hasta esta fórmula del Estado-nación, propia del mundo contemporáneo. Por esa razón, hay autores como Corrigan y Sayer que han llegado a concebir la construcción histórica del Estado (en su caso, el Estado inglés) como una verdadera revolución cultural".26

\section{A "revolución española" (1808-1840)}

A partir dessas premissas, na segunda, terceira e quarta partes do texto (El caso español: de la Monarquía al Estado-Nación; Hacia la construcción material del Estado: la Administración, e Estado, mercado, nación), a narrativa define onde/como/sob comando de quais personagens se moldou na Espanha essa forma de Estado, ressaltando que "la construcción del Estado nacional del siglo XIX no fue una continuidad o perfeccionamiento de un proceso iniciado anteriormente". Para tanto, particulariza situações de "rupturas" políticas identificadas com acentuadas transformações nas práticas daquele Estado, e também sua importância na composição de novos conceitos, imagens e símbolos nacionais. Lembro algumas destas situações que assinalam a percepção de "rompimento" com o passado.

A primeira delas diz respeito ao período da "revolución española (1808-1814)" (denominação criada pelos contemporâneos) momento em que se registrou um "vazio de poder" - decorrente da invasão estrangeira, da abdicação do rei e da resistência popular -, rapidamente ocupado por Juntas locais e por representantes de todo o império, pouco depois reunidos nas Cortes de Cádiz (1812). Nesta circunstância ter-se-ia ensaiado, por algum tempo, uma mudança estrutural do império e do regime, rompimento mais visivel nos territórios americanos da monarquia que aos poucos foram conquistando sua independência. ${ }^{27}$

A segunda situação constitui interregno com várias décadas de duração (1814-1840), durante o qual, mediante várias tentativas, ocorreu a definição material de uma nova forma de Estado centralizado, autoritário e desvinculado da maior parte das antigas áreas coloniais. Foi possivel pela lenta e, decisiva, implantação de medidas de impacto econômico, social e político, sendo a principal delas a autonomia financeira do governo pelo acesso a recursos obtidos com a alienação de terras e rendas antes em poder da Igreja e das elites senhoriais locais. Tal expediente possibilitou resolver em parte a divida pública e financiar órgãos, corpo de funcionários e forças militares geridos pelo poder central. Esta nova forma de Estado concretizou-se a partir da década de 1830 com uma nova divisão provincial, decidida em 1833 - bem sucedida pela atuação de Javier de Burgos; com o reconhecimento das independências das colônias americanas, acertado em 1836; e, principalmente, com a desamortização dos bens da Igreja, a reforma do clero e a substituição dos dízimos por um imposto para a manutenção do clero secular (de 1835) e de outros gastos, processo no qual se projetou a figura do líder liberal "progressista" Juan Álvarez Mendizábal. A estas decisões acrescentaram-se a abolição definitiva dos senhorios, a eliminação das Ha- 
No qual se destacam Alejandro Oliván, Ramón de Santillan, Antonio Gil de Zárate, Javier de Burgos, Manuel Ortiz de Zúñiga.

31

Propostas por Bonin, Cormelin, Bouron-Leblanc, Gaudillot, Macarel.

\section{2}

PRO RUIZ, Juan. La construcción del Estado em España... Op.cit.

33

Ibidem. ciendas senhoriais e a Constituição de 1837, pré-requisitos para a afirmação do regime monárquico constitucional.

Acompanhando o processo de modelação material desta nova forma de Estado, o autor arrola outras providências que imbricaram objetivo imaterial e subjetivo essencial, ou seja, medidas destinadas a "inscribir el Estado en las mentes de los ciudadanos", e assim constituir uma "mentalidade nacional". Nesta direção, a rede de instrução pública uniformizou cultural e linguisticamente o pais, "haciendo de él una nación en la que imperaram imaginários similares." A narrativa ainda inclui iniciativas para criar um mercado nacional único "que diera también sentido económico a la unificación legislativa y cultural", como a reforma tributária de 1845, a unificação monetária, a criação dos selos e do Banco de Espanha (1856), as realizações em matéria de estatística e cartografia (mapas da população e do território) ; além da implementação de uma rede de estradas de ferro. Todas elas seriam experiências de grande impacto simbólico, imprescindiveis tanto para a percepção de um "mercado nacional" quanto para a uniformização de mentalidades e da cultura. ${ }^{28}$

No entanto, a perspectiva de "ruptura" e de "mudança estrutural" que domina as primeiras partes do texto recua substancialmente na narrativa a partir do final do quarto tópico (que trata da instrução pública) e, também, no quinto -- "Los modelos em competência: imaginários de Estado"--, quando elabora contraponto entre projetos e partidos que atuaram na construção deste Estado-Nação. 0 texto arrola, então, o Partido Progressista, a opção liberal modelar pelos preceitos "descentralizadores" e "democráticos", com curtíssima passagem pelo poder. 0 Partido Moderado, presença frequente no governo, defensor de um "modelo bonapartista e autoritário de estado" que conciliou algumas mudanças liberais com importantes dispositivos do Antigo Regime, em destaque a centralização política autoritária atrelada a interesses dos mandatários locais. 0 Partido Carlista, opção "absolutista" e "reacionária", signatário do passado que, embora derrotado militarmente na guerra civil, ainda conservou grande vigor politico nas províncias do norte. 0 Partido Demócrata, refúgio de monarquistas liberais e republicanos herdeiros marginalizados dos preceitos da exemplarmente liberal Constituição gaditana de 1812; e a Unión Liberal, agremiação de moderados e progressistas em busca de uma terceira via centrista, eclética, pragmática. ${ }^{29}$

Neste tópico do texto registram-se alguns impulsos de ruptura já comentados, levados a termo pelos Progressistas entre 1835-1837. Contudo, após a apresentação dos feitos deste grupo político, o autor enfatiza que prevaleceram, senão imperaram nos governos da "década moderada" (1844-1854) e nas seguintes (durante a Restauración) iniciativas conciliadoras, ou recuperadoras de práticas remanescentes do Antigo Regime. Tais orientações se consolidaram com a Ley dos Ayuntamientos (1845), um dos dispositivos do ideal administrativo de "Estado Grande" estabelecido entre 1856 e 1868 em modelo desenhado por grupo político vinculado ao Partido Moderado $^{30}$ inspirado nas orientações do "administrativismo francês ${ }^{31 ", ~ a o ~}$ qual foram associadas "prácticas locales del gobierno político y económico de los pueblos asentadas en la España del Antíguo Régimen"32. Na verdade, segundo a análise, o Estado-Nação teria sido moldado pela duradoura atuação dos Moderados com projeto que amalgamou, sob o signo de uma ordem até "involucionista" e "autoritária"33, orientações bonapartistas com práticas tradicionalmente hispânicas, em obra consolidada pela Unión Liberal durante a Restauración. Entretanto, apesar dos Moderados terem estado à testa 
do poder por mais tempo, todos os partidos acabaram por respeitar as "práticas tradicionalmente hispânicas" cristalizadas no poder das forças locais:

\begin{abstract}
"Aquel localismo original quedó impreso a fuego en el Estado contemporáneo y en todos los programas que pugnaban por orientar su construcción, aunque esa presencia se manifestara de maneras diversas, como ya hemos visto: los moderados, que soñaban con un Estado grande basado en una administración centralista, uniforme y eficaz, y que mantuvieron esa ficción jurídica, se tuvieron que contentar en la práctica con una confederación de oligarquias locales y provinciales que negociaban con el poder central su colaboración en las tareas del Estado; los progresistas hicieron de la descentralización una de sus banderas políticas más sonadas, proponiendo la autonomía municipal como panacea de la libertad moderna; los carlistas pretendian una Monarquía en la que todo el poder se concentraría en la Corona, pero toda la administración quedaría delegada en los municipios y provincias; los demócratas, que cultivaban el ideal descentralizador de los progresistas, engendraron en su seno un republicanismo federal y una insurgencia cantonalista (1873-74) que llevaron la soberania local hasta el extremo; y los unionistas se las ingeniaron para combinar el municipalismo doctrinal de los progresistas con el clientelismo descentralizador que practicaban tanto éstos como los moderados, dando lugar al caciquismo de los comienzos de la Restauración, paraíso de los oligarcas locales". ${ }^{34}$
\end{abstract}

\title{
3. Novidade e tradição: contradições da experiência liberal na Espanha
}

\section{4}

lbidem.

35

LEFORT, Claude. Op. Cit. p.17-18.

36

$\mathrm{Na}$ concepção de Antigo Regime o autor acompanha ARTOLA GALLEGO, Miguel. Antíguo Régimen y revolución liberal. Op.Cit. Em obra posterior, citada no texto, Artola alterou a primeira periodização restringindo o Antigo Regime ao século XVIII, período da dinastia Bourbon. ARTOLA, Miguel. La monarquia de España. Madrid: Alianza Editorial, 1999.
Muito diferente e importante, a meu ver, é a exigência de retomar o senso $d a$ complicação; ser receptivo às mudanças que advêm em nosso tempo, sem ceder à ilusão de uma ruptura radical entre presente e passado, mas, ao contrário, procurando auxilio nos pensadores que sabiam interrogar seu próprio tempo; explorar as novas relações que se tecem entre a política, a economia, o direito, a ciência, a arte, as crenças e os hábitos, sem se deter nas definições aceitas que se atribuem a cada um desses domínios e, no entanto, sem ignorar a distinção entre eles." ${ }^{\text {35 }}$

Principiando minhas considerações, observo que na situação espanhola parecem ter-se (re)modelado representações e vínculos nos quais imperaram princípios e práticas políticas herdados do Antigo Regime, tanto no perfil como foi vivenciado no período dos Habsburgos (séculos XVI e XVII) quanto do "reformismo ilustrado" dos Bourbons (século XVIII) ${ }^{36}$. Como visto, ressaltam-se dentre elas a admissão do localismo, mais tarde denominado caciquismo, e do autoritarismo, princípios (re)trabalhados por quase todos os projetos políticos apresentados. A argumentação admite, também, a falência da educação laica (meio significativo na conformação e difusão de uma mentalidade nacional) e a consequente recuperação das instituições religiosas de ensino, experiências que colocam em dúvida, ou pelo menos (re)definem a concepção de ruptura revolucionária mais evidente, ou seja, aquela que estabelece acentuada dessemelhança entre presente e passado. Mais ainda, a persistência do localismo enquanto princípio político parece questionar a efetiva presença de uma "mentalidade" ou cultura "nacional".

Embora a argumentação não referencie objetivamente as matrizes que informam o entendimento da expressão "ruptura" mental e política com o Antigo Regime -- muito importante na primeira parte da análise --, Pro Ruiz parece inspirar-se na interpretação sobre a "modernidade" lançada pela história dos conceitos de Reinhart Koselleck, segundo a qual, a partir do século XVIII e tendo-se em vista a luta contra o Absolutismo, emerge inédita compreensão do "tempo" e da "história,": o passado deixa de ensinar e de projetar-se no futuro. Acompanhando a moldagem da ideia de "progresso" 
37

KOSELLECK, Reinhart. Futuro passado.

Contribuição à semântica dos tempos históricos. Trad. Wilma Maas e Carlos Almeida Pereira. Rio de Janeiro: Contraponto- PUC-Rio, 2006. p.14-18. "El futuro ya no resultaria legible en las experiencias del pasado. [...] pero el hecho fundamental que precipitó la quiebra definitiva del concepto de historia magistra vitae fue el estalido de la Revolución Francesa de 1789. Ésta determinó la emergencia de una nueva perspectiva histórica en la medida en que afirmó lo que Koselleck definió como la idea de constructibilidad de la historia." PALTI, Elias Jose. Introducción. In: KOSELLECK, Reinhart. LOS estratos del tiempo: estudios sobre la historia. Barcelona: Ediciones Paidós/ I.C.E.; Universidad Autónoma de Barcelona, 2001. p.20.

\section{8}

ARENDT, Hannah. Da Revolução. Trad. José Roberto Miney. Brasilia: Ed.UnB; São Paulo: Ática, 1988.

39

MARSON, Izabel Andrade. Hannah Arendt e a revolução: ressonâncias da Revolução Americana no Império Brasileiro. IN: DUARTE, André; LOPREATO, Christina; MAGALHÃES, Marion B. (orgs.). A banalização da violência: a atualidade do pensamento de Hannah Arendt. Rio de Janeiro: Relume Dumará, 2004. p. 227

40

"[...] mas essa mesma herança ordena, para salvar a vida (...) que se reinterprete, critique, desloque, isto é, que se intervenha ativamente para que tenha lugar a transformação digna deste nome; para que alguma coisa aconteça, um acontecimento, da história, do imprevisivel por-vir". ROUDINESCO, Elisabeth; DERRIDA, Jacques. De que amanhã?...Diálogo Elisabeth Roudinesco-Jacques Derrida. Rio de Janeiro:Zahar, 2004. p. 13.
- princípio crítico da história magistra vitae até então dominante - o futuro não se identifica mais como "futuro passado", mas transforma-se em temporalidade de concretização de utopias laicas viabilizadas pela atuação dos cidadãos nos espaços políticos. ${ }^{37}$

No entanto, a considerar-se o conjunto da argumentação, particularmente a narrativa histórica que integra as últimas partes do texto, o sentido deste "rompimento" assume perfil mais complexo por sinalizar a alternativa de vivenciar-se a "ruptura" política e mental que alicerça o Estado-nação preservando-se mediações com o passado, ou com práticas e, mesmo, principios nele vigentes. Esta possivel leitura nos sugere outras matrizes explicativas também provindas da filosofia política, a exemplo de Hannah Arendt que, em Da Revolução, explora ambiguidades históricas implícitas nesta categoria. Assim, no que diz respeito ao desempenho dos cidadãos proprietários durante a revolução americana, Arendt reconhece o traço "revolucionário" liberal -- ou o aspecto histórico " novo" - na determinação daqueles personagens de romperem integralmente com pacto colonial tendo por meta preservar direitos adquiridos e realizar novos desígnios. Entretanto, a autora também frisa o quanto esta liberdade, intrinsecamente associada à propriedade de bens, não pode prescindir da continuidade zelosamente mantida da escravidão de africanos, fenômeno, aliás, que também ocorreu na experiência brasileira. ${ }^{38}$

É extremamente instigante o desdobramento dos sentidos, imbricados em expressões chave emergentes na argumentação revolucionária, realizado por Arendt, como revolução, constituição, liberdade, violência, poder, autoridade. Ao decompor conteúdos cristalizados nestes termos, comparar as experiências francesa e americana valorizando as características do lugar, do tempo e da tradição a partir dos quais foram engendradas, e apontar aproximações e especificidades, sua leitura dos eventos revolucionários do final do século XVIII alargou sobremaneira um paradigma consagrado sobre as revoluções liberais, estabelecido tanto por matrizes liberais quanto marxistas, que erigiram uma dada concepção dos acontecimentos franceses de 1789-1800 como modelo universal de revolução. ${ }^{39}$ Além de Arendt, penso que também é possivel entender a complexidade da expressão "ruptura" veiculada no texto a partir do conceito de "criação" de Jacques Derrida, que concebe o ato de criar como (re)elaboração de heranças do passado tendo-se em vista solicitações do presente $^{40}$ Lembro ainda a ênfase conferida por Claude Lefort ao "senso de complicação" inscrito na relação presente/ passado quando analisada com sensibilidade histórica (ou ao "histórico), conforme registram os trechos das epígrafes deste comentário.

Buscando vestígios deste complexo e contraditório rompimento com o passado observo que, embora a narrativa não explore, como manifestação de "mudança estrutural", as alterações convencionalmente concebidas como "mudanças econômicas", visíveis na Espanha (entre a segunda metade do século XVIII e primeira do XIX), elas me parecem implícitas nos eventos político-administrativos comprobatórios da "ruptura" política e, sobretudo, cultural. Isto porque, uma vez libertos de um estrito sentido "material", é possivel reconhecer importantes qualidades subjetivas nos "acontecimentos econômicos". Neste sentido, as transformações registradas nas "relações de produção" na Espanha do XVIII e XIX certamente despertaram paixões e expectativas revolucionárias essenciais nas mobilizações que reivindicaram como, quando e onde aconteceria a construção desta nova forma de Estado ${ }^{41}$. Ainda, a desagregação dos relacionamentos comunitários e corpo- 
Estudioso do desempenho dos sentimentos e das paixões na política moderna o sociólogo Pierre Ansart demonstra sua presença e importância na argumentação de vários clássicos, dentre eles Karl Marx; tanto nas obras teóricas quanto nas históricas e políticas. ANSART, Pierre. Karl Marx: la passion révolutionnaire. In: ANSART, Pierre. Les Cliniciens des passions politiques. Paris:Éditions Du Seil, 1997. p. 149-177. A temática é tratada também em ANSART, Pierre. La gestion des passions politiques. Lausanne:L'Age d'Homme, 1983.

42

ARTOLA GALLEG0, Miguel. Antíguo Régimen y revolución liberal. Op. Cit.

43

PALTI, Elias José. El absolutismo monárquico y la génesis de la soberanía nacional. In: NAXARA, Marcia; CAMILOTTI, Virgínia. (Orgs.). Conceitos e Linguagens: construções identitárias. São Paulo: Intermeios-Capes, 2013. p. 33-52; FRANCO, Maria Sylvia de Carvalho. "All the world was America". John Locke, liberalismo e propriedade como conceito antropológico. Revista USP. São Paulo: USP, 1993, n. 17. p. 31-53; TOMICH, Dale. Pelo prisma da escravidão. Trabalho, capital e economia mundial.Trad. Antonio de Pádua Danesi. Ver. Rafael de Bivar Marquese. São Paulo:Edusp, 2011. rativos do conjunto da sociedade espanhola sob o Antigo Regime -- relacionamentos complexos, a um só tempo materiais, políticos, religiosos e sentimentais - instigou novas subjetividades, abertas e sensiveis à constituição da "mentalidade nacional".

Nesta problemática, que aproxima história, economia e política, a narrativa estabelece criativo diálogo com Miguel Artola a propósito do tema "revolução liberal", parecendo respeitar desta referência, a periodização da "revolução " - 1808-1840; o histórico de dificuldades para a concretização das reformas que viabilizaram o "projeto progressista" de Estado-nação tanto as econômicas quanto as políticas; o perfil "autoritário" da monarquia constitucional efetivamente implantada; a importância das reformas desmobilizadoras dos apoios político-sociais do Antigo Regime que garantiram autonomia financeira aos novos governantes. Privilegiando as conquistas "materiais" que constituíram o estado liberal na Espanha, em Antiguo Régimen y revolución libera ${ }^{42}$, Artola acentua justamente a dimensão de ruptura inscrita nas decisões políticas e na legislação que desamortizou bens dos religiosos e terras comunais preparando assim um "mercado nacional" de bens (terras e trabalho) e da própria produção. Frisa ainda o impacto das medidas que aboliram o controle de preços de produtos agrícolas ou artesanais pois, associadas, reverberaram profundamente no modo de vida, nos comportamentos e na composição da sociedade: ampliaram os contingentes de assalariados rurais e urbanos e promoveram as burguesias agrícola e industrial, sendo que, estas últimas se tornaram suportes da revolução liberal de matiz autoritário e conciliador com o passado. Ou seja, percebem-se novos grupos, novos papeis políticos, novas sensibilidades, comportamentos e mentalidades.

Entendo que a iniciativa de superar o "divórcio" entre tradições interpretativas - econômicas, políticas e culturais - no caso da Espanha, pode contemplar esta "revolução social" de tantos significados para as mentalidades e percepção do nacional, campos bem explorados no texto. Partindo deste pressuposto, e considerando, com Arendt e muitos outros autores ${ }^{43}$, que não há necessariamente uma relação de negação entre liberalismo, autoritarismo e valorização do poder local, os traços denotativos das "continuidades" e heranças do Antigo Regime apontados no texto poderiam ganhar outros significados históricos, de certa forma sinalizados na narrativa, que chega a registrar uma imprescindivel aproximação entre os tradicionais poderes locais e o Estado liberal na condução dos eventos revolucionários e na construção de novo pacto político:

\footnotetext{
"Durante todo ese tiempo [1810-1840], el poder de hecho fue asumido por oligarquias locales semi-independientes apenas supervisadas por un poder central intermitente e inoperante, en proceso continuo de redefinición institucional y con graves dificultades para hacer reconocer su legitimidad. La construcción del Estado pasaba por la negociación y la integración de las oligarquías locales únicas que podrían asegurar el control del territorio y la movilización de sus recursos".[...]

Las identidades locales habian sido desde antiguo la base para la noción de naturaleza en los reinos de la Monarquía. El tránsito al régimen liberal se hizo mediante procesos revolucionarios que tuvieron una importante base local, demostrando que era ese ámbito el que concitaba las lealtades primordiales: la revolución la dirigieron juntas locales y provinciales, que sólo después de ver aseguradas sus reclamaciones básicas aceptaron ceder el poder a algún órgano de ámbito nacional. ${ }^{44}$
} 
PRO RUIZ, Juan. La construcción del Estado em España... Op.cit.

45

MARSON, Izabel Andrade. A natureza como artificio: tramas de conceitos e linguagens na tessitura da questão nacional na Europa e na América In: NAXARA, Marcia; CAMILOTI, Virgínia. (Orgs). Op. Cit. p. 51-68.
No que diz respeito às relações entre Estado, Sociedade Civil e Cultura Política a análise também projeta duas situações contrastantes que gostaria de comentar. Mais amiúde, os "atores históricos", planejadores e implementadores do Estado-nação, aparecem representados por amplas figuras políticas - os partidos, o Exército, a Guarda civil, o clero, os senhorios, as oligarquias, figuras que se relacionam com um Estado-demiurgo remetido a alguns personagens -- Javier de Burgos, Mendizábal, dentre outros -- a quem se atribui intervenções uniformizadoras e modeladoras do "nacional". Salvo registro de poucos recuos na implementação das medidas de efeito "cultural"- a exemplo do sistema educacional laico - ao expor como foi delineada uma "mentalidade coletiva" (item Estado, Mercado, Nación) a argumentação ressalta decisões governamentais bem sucedidas (os sistemas fiscal, monetário, a unificação linguística) invariavelmente propostas por chefias partidárias.

No entanto, outras passagens enfatizam complexo e vigoroso relacionamento de mão dupla, entre Estado, Sociedade civil e Cultura Política, constatação com a qual concordo. Uma primeira demonstração desta complexidade aparece justamente na (re)modelação das práticas tradicionais, que já comentamos. Outra emerge em circunstâncias de grande repercussão política, nomeadas "movimentos revolucionários", mas pouco exploradas. Nelas membros desta sociedade, sem perfil preciso, se mobilizam para contestar, com sucesso, decisões que embaraçavam a atuação dos conselhos locais ou direitos dos cidadãos ao exercício da política. ${ }^{45}$ Penso o quanto poderia ser proveitoso o diálogo entre a história cultural do político e a história cultural da política no sentido de esclarecer esta complexa e transformadora relação de mão dupla que, me parece, expressa com clareza mudanças nos comportamentos e sensibilidades políticas, indicativas de uma "mentalidade nacional".

Finalizando, quero reiterar a importância das contribuições deste trabalho que explora potencialidades da história cultural do político para a releitura do liberalismo na Espanha. Retomo a problematização de paradigmas "mecanicistas" ou concepções restritivas do Estado-nação que estabeleceram situações liberais modelares discriminadoras das experiências aparentemente distantes daquelas situações, como é o caso de Espanha, Portugal e também de suas áreas coloniais ${ }^{46}$. Retomo também a importante decisão de superar o "divórcio existente entre tradições interpretativas" de diverso matiz sobre o objeto Estado-nação. Neste sentido, as observações aqui apresentadas somam esforços com as colocações do texto em seu intuito de "mostrar las posibilidades que ofrece una perspectiva cultural da construcción del Estado Nacional en España".46

Em meu entender a iniciativa de "demonstrar possibilidades" se adequa ao "estado da arte" em que hoje se encontram os estudos da história cultural do político, conforme anuncia George Steinmetz na Introdução da coletânea State/Culture. State formation after the Cultural Turn, ao enfatizar o quanto as mediações entre Estado e Nação têm entendimentos muito diversos entre os estudiosos que a elas se dedicam:

\footnotetext{
"Some of the writers represented in this collection make powerful claims for the shaping of states by culture, whereas others emphasize causal flows running in both directions - and some reject the analytical distinction between culture and nonculture altogether."47
} 
FUKUYAMA, Francis. 0 fim da história e o último homem. Rio de Janeiro:Rocco, 1992.
Neste debate, é importante reter a inventiva imbricação das ciências sociais em seu empenho de comprovar tanto a instigante história que 0 Estado-nação e o liberalismo constituíram no passado quanto a que, a despeito dos que anunciaram seu $\mathrm{fim}^{48}$, ainda continuará a percorrer. Neste recorrente "combate pela história", os estudos sobre as realizações culturais do político e da política certamente constituem promissores campos de investigação.

\section{Bibliografia}

ANSART, Pierre. Karl Marx: la passion révolutionnaire. In: ANSART, Pierre. Les Cliniciens des passions politiques. Paris:Éditions Du Seil, 1997.

Pierre. La gestion des passions politiques. Lausanne:L'Age d'Homme, 1983.

ARENDT, Hannah. Da Revolução. Trad. José Roberto Miney. Brasília: Ed.UnB; São Paulo: Ática, 1988.

ARTOLA GALLEG0, Miguel. La monarquia de España. Madrid: Alianza Editorial 1999.

. Miguel (dir.); PÉREZ LEDESMA, Manuel. (col.); PRO RUIZ, Juan (col.). Enciclopedia de historia de España. Madrid:Alianza Editorial, 1988, vol. 6. p. 1095-1176; 1209-1237.

Miguel. Antíguo Régimen y revolución liberal. Barcelona: Editorial Ariel, 1991.

BALAKRISHNAN, Gopal; ANDERSON, Benedict. (orgs.). Um mapa da questão nacional. Trad. Vera Ribeiro. Rio de Janeiro: Contraponto, 2000.

CATROGA. Fernando. Pátria, Nação, Nacionalismo. In: TORGAL, Luís R.; PIMENTA, Fernando T.; SOUSA, Julião S. (coord.). Comunidades Imaginadas. Nação e nacionalismo em África. Coimbra: Imprensa da Universidade, 2008.

CORRIGAN, Philip; SAYER, Derek. The Great Arch: English state formation as cultural revolution. Oxford:Blackwell, 1985.

DÉLOYE, Yves. A cidadania europeia sob o prisma de suas fronteiras [ou] como pensar o pertencimento político em um mundo póswestfaliano. In: NAXARA, Marcia; MARSON, Izabel; BREPOHL, Marion. (orgs.). Indiferenças. Percepções políticas de um sentimento. São Paulo:Intermeios, 2015.

FEBVRE, Lucien. Combats pour l'Histoire. Paris: A.Collin, 1953.

FRANCO, Maria Sylvia de Carvalho. "All the world was America". John Locke, liberalismo e propriedade como conceito antropológico. Revista USP. São Paulo: USP, 1993, n. 17. p. 31-53. 
FUKUYAMA, Francis. O fim da história e o último homem. Rio de Janeiro:Rocco, 1992.

JANCSÓ, István. (org.). Independência: história e historiografia. São Paulo: Hucitec:Fapesp, 2005.

KOSELLECK, Reinhart. O futuro passado. Contribuição à semântica dos tempos históricos. Trad. Wilma Maas e Carlos Almeida Pereira. Rio de Janeiro: Contraponto- PUC-Rio, 2006.

LEFORT, Claude. Pensando o político. Ensaios sobre democracia, revolução e liberdade. Trad. Eliana M. de Souza. Rio de Janeiro:Paz e Terra, 1991.

MARSON, Izabel Andrade. Hannah Arendt e a revolução: ressonâncias da Revolução Americana no Império Brasileiro. IN: DUARTE, André; LOPREATO, Christina; MAGALHÃES, Marion B. A banalização da violência: a atualidade do pensamento de Hannah Arendt. Rio de Janeiro: Relume Dumará, 2004.

- Izabel Andrade. A natureza como artifício: tramas de conceitos e linguagens na tessitura da questão nacional na Europa e na América In: NAXARA, Marcia; CAMILOTII, Virgínia. (Orgs). Conceitos e Linguagens: construções identitárias. São Paulo: Intermeios-Capes, 2013. p. 51-68.

PALTI, Elias José. La nación como problema. Los historiadores y la "cuestión nacional". México: Fondo de Cultura Económica, 2003.

Elias Jose. Introducción. In: KOSELLECK, Reinhart. Los estratos del tiempo: estudios sobre la historia. Barcelona: Ediciones Paidós - I.C.E.; Universidad Autónoma de Barcelona, 2001.p.9-34.

Elias José. El absolutismo monárquico y la génesis de la soberanía nacional. In: NAXARA, Marcia; CAMILOTTI, Virgínia. (Orgs.). Conceitos e Linguagens: construções identitárias. São Paulo: Intermeios/Capes, 2013. p. 33-52.

PÉREZ LEDESMA, Manuel; SIERRA, Maria.(eds.). Culturas políticas: teoria e historia. Zaragoza:Institución Fernando el Católico, 2010.

ROUDINESCO, Elisabeth; DERRIDA, Jacques. De que amanhã?...Diálogo Elisabeth Roudinesco-Jacques Derrida. Rio de Janeiro:Zahar, 2004.

STEINMETZ, George. (ed.). State/Culture. State formation after Cultural Turn. Ithaca/London:Cornell University Press, 1999.

TOMICH, Dale. Pelo prisma da escravidão. Trabalho, capital e economia mundial. Trad. Antonio de Pádua Danesi. Revisão Rafael de Bivar Marquese. São Paulo:Edusp, 2011.

XAVIER-GUERRA, François; ANNINO, Antonio. (orgs.). Inventando la nación: Iberoamérica. Siglo XIX. México: Fondo de Cultura Económica, 2003. 